Hall, D. H., Fucci, D. J., \& Arnst, D. J. Vibrotactile stimulation: An investigation of psychophysical methods for establishing threshold. Perceptual \& Motor Skills, 1972, 34, 891-898.

Hilgard, E. R., \& Atkinson, R. C. Introduction to psychology. New York: Harcourt, Brace, \& World, 1967.

Mysak, E. D. Speech pathology and feedback theory. Spring field, Illinois: Thomas, 1966.

Ringel, R., \& Ewanowski, S. Oral perception: 1. Two-point discrimination. Journal of Speech \& Hearing Research, 1965, 8, 389-398.

Van Riper, C., \& Irwin, J. Voice and articulation. Englewood
Cliffs, New Jersey: Prentice-Hall, 1962.

Verrillo, R. T. Effect of contactor area on the vibrotactile threshold. Journal of the Acoustical Society of America, $1963,35,1962-1966$.

Verrillo, R. T. Vibrotactile sensitivity and the frequency response of the Pacinian corpuscle. Psychonomic Science, $1966,4,135-146$.

(Received for publication December 28, 1973.)

\title{
Forgetting of visually presented words after retention intervals filled with detection of acoustic signals*
}

\author{
BARRY LESHOWITZ and PATRICK M. ZUREK $\dagger$ \\ Arizona State University, Tempe, Ariz. 85281
}

and

\author{
DONALD ROBBINS \\ Emory University, Atlanta, Ga. 30322
}

Recall of common one-syllable words following an interpolated interval of either 15 or $30 \mathrm{sec}$ was investigated. Two filler tasks were used: a simple detection task (tone in noise) or discrimination of tonal amplitude. Of the $20 \mathrm{Ss}, 10$ showed appreciable forgetting. These data question the conclusion that memory loss due to the passage of time does not occur in short-term memory.

Recently, Reitman (1971) developed a procedure to study the possible loss of information from short-term memory when the effects of interference and rehearsal are minimized or eliminated. Specifically, she asked: Does information in short-term memory decay as a result of the passage of time? In order to eliminate rehearsal, Reitman used a modification of the Peterson \& Peterson (1959) paradigm. Stimulus material (to-be-recalled) was presented to S, followed by a $15-\mathrm{sec}$ filler task designed to prevent rehearsal and to interfere minimally with the to-be-remembered material. She used three different filler tasks. One was the detection of a pure tone in a continuous background of white noise, while the other two tasks were the detection of the spoken syllable "toh" in a background of "dohes"; one condition required $\mathrm{S}$ to press a key as soon as a "toh"

\footnotetext{
*This research was supported by United States Public Health Service Grant MH 20301 and by a contract from the Human Resources Laboratory, Flying Training Division at Williams Air Force Base in Arizona.

tRequests for reprints should be sent to: Barry Leshowitz, Department of Psychology, Arizona State Univeristy, Tempe, Ariz. 85281 .
}

was heard, while for the second condition $\mathrm{S}$ had to also say "toh" aloud.

Reitman (1971) found very little forgetting after $15 \mathrm{sec}$ for the tone-detection filler task, but found some for the syllable filler tasks. Mean retention in tone detection was $92 \%$, and for the syllabic identification task it was about $75 \%$. In the tonal-detection experiment, when no signal was presented in the retention interval and no false alarms were recorded, 13 Ss actually showed $100 \%$ recall while the remaining 5 showed between $67 \%$ and $89 \%$ recall. Atkinson \& Shiffrin (1971) reported replicating Reitman's results using the tone-detection filler task for intervals of 1,8 , and $40 \mathrm{sec}$.

Reitman (1971) and Atkinson \& Shiffrin (1971) concluded, based on these data, that there is no support for the proposition of temporal loss in short-term memory. Because this conclusion has important implications for theories of the memorial process, we must not minimize the importance of a basic assumption that is being made with regard to the control of rehearsal. Both Reitman (1971) and Atkinson \& Shiffrin (1971) told Ss not to rehearse during the detection interval. In fact, Reitman's (1971) data are based on 18 Ss who said, on a posttask questionnaire, that they did not rehearse. She eliminated the data of 13 Ss who said that, contrary to instructions, they had indeed rehearsed. As mentioned earlier, although 13 of Reitman's Ss in the tone detection filler task recalled $100 \%$ of the words when the retention interval was empty, 5 of them did show forgetting. This represents a considerable amount of variability between Ss and may reflect the distribution of the ability of a $S$ to rehearse the verbal material and simultaneously do the signal-detection task. It does not seem unreasonable to argue that nonverbal acoustic information may be processed independently of verbal material presented visually. Thus, rehearsal of the verbal material would 
Table 1

Proportion Correct (P), Reaction Time in Milliseconds (RT), and $d^{\prime}$ for the 15- and 30-Sec Vigilance and Discrimination Conditions and for the 0-Sec Interpolated Interval

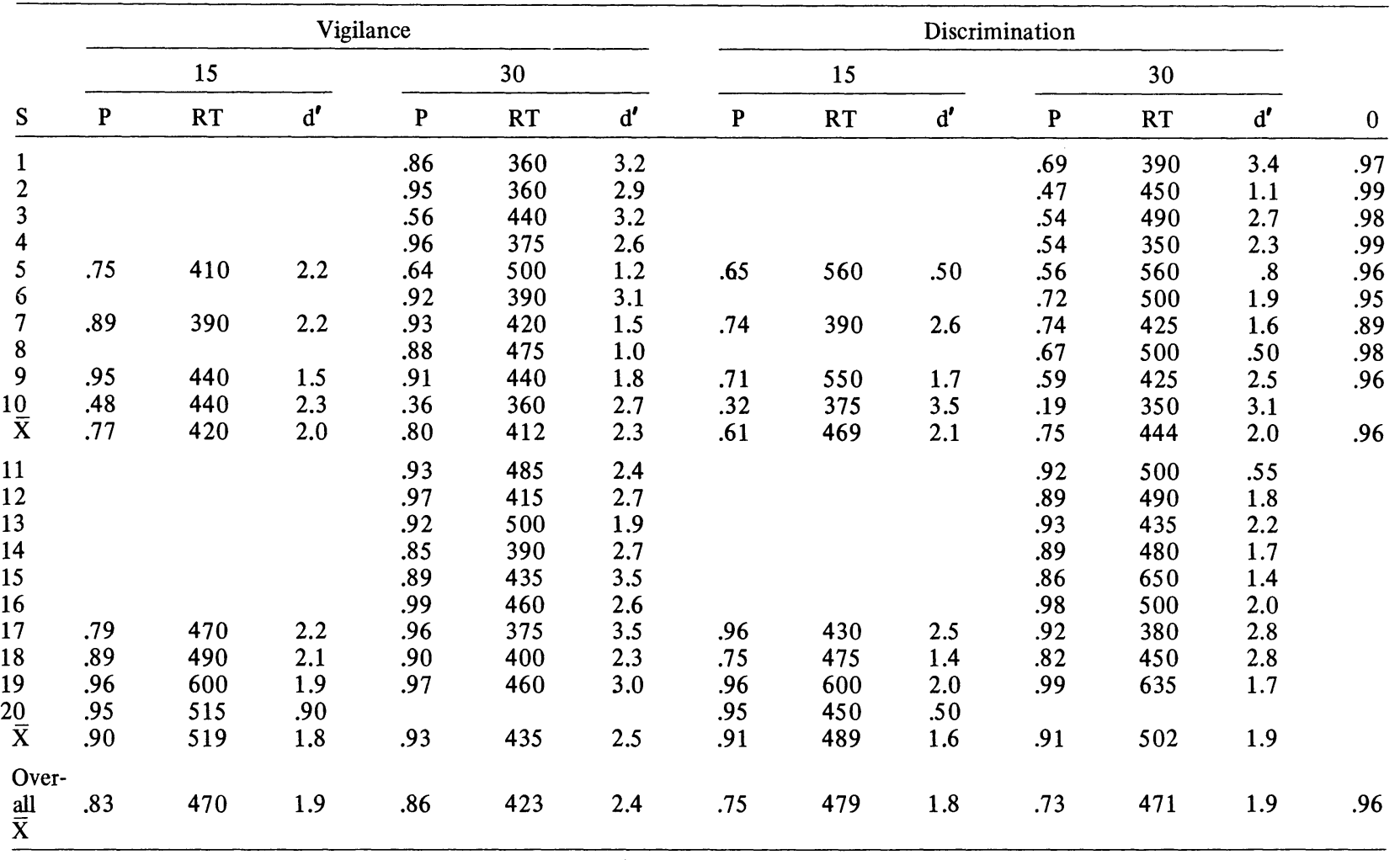

Note-(a) Each recall score (P) is based on 108 observations. (b) Reaction time and detectability data are based on performance for the last 10 trials in each block of 12 trials. (c) Ss 9, 17, and 19 were practiced auditory observers. (d) Ss numbered 1-10 showed a substantial amount of forgetting.

prevent decay that would normally occur due to the passage of time.

In the present study, we will present data to show that some Ss exhibit forgetting over intervals of 15 or $30 \mathrm{sec}$ of a detection task while others do not. At the least, these data should bring into question the generality of the conclusion that loss due to the passage of time per se does not occur in short-term memory. It is speculated that the detection filler task permits $S$ to time-share, and thus to increase the amount of information in long-term memory. Consequently, the Reitman (1971) and Atkinson \& Shiffrin (1971) "short-term" functions actually represent information from a long-term store as well as a short-term store.

\section{METHOD}

Apparatus and Procedure

Recall was measured using an experimental paradigm similar to that developed by Reitman (1971). The material to be recalled was three four-letter monosyllabic English words, given by Reitman (1969). An experimental trial began with the presentation via earphones of a 70-dB background noise, which lasted for the duration of the trial. Two seconds later, an " $M$ " appeared on an oscilloscope screen situated in front of $\mathrm{S}$. The three stimulus words were then presented simultaneously for 2 sec. A retention interval then followed. The letter "W" signaled the end of the retention intervat and served as a cue for $S$ to type the three words on the Teletype. After the words were typed, the noise ceased, marking the end of the trial. Trials were separated by a 7 -sec rest period.

Each 2-h experimental session consisted of six blocks of 12 trials. A block of trials was devoted to measuring recall following a retention interval in which Ss participated in either a vigilance or discrimination task. In the vigilance task, a $250-\mathrm{msec} 56.5-\mathrm{dB}$ $1,000-\mathrm{Hz}$ tone was to be detected in the presence of a background noise, whose level was $70 \mathrm{~dB}$. In the discrimination task, a 56.5-dB 250-msec tone was presented twice per second, with an on-off ratio of one-half. The increment to be detected was a $6.5-\mathrm{dB}$ increase in the level of the tone burst. Signal levels were not tailored for each individual $S$. Signal levels were adjusted in the two tasks to produce a detectability score, $d^{\prime}$, of about 2.0 (Swets, 1964) for all Os.

In an experimental session, the retention interval was fixed, and vigilance and discrimination conditions were alternated. The length of the retention interval was either 15 or $30 \mathrm{sec}$. In all, there were four conditions: $15 \mathrm{sec}$, vigilance; $15 \mathrm{sec}$, discrimination; $30 \mathrm{sec}$, vigilance; and $30 \mathrm{sec}$, discrimination. Two sessions were required to complete the four conditions. However, not all of the Ss served in all four conditions. Assignment of Ss to the four conditions is shown in Table 1. It should be noted that the numbers assigned to Ss in Table 1 do not represent order of appearances for the study or order of running. The Ss were numbered in this manner for ease of presentation.

Both detection tasks represent free-response paradigms in which a well-defined observation period does not exist. An observation interval was defined as a 1-sec interval in which a signal could be presented. In the discrimination tasks, the observation period began at onset of the first, third, fifth, etc., tone burst. Unknown to the $S$, even-numbered tone bursts never contained a signal. In the detection task, the $1-\mathrm{sec}$ observation 
period began at onset of a potential signal. Thus, the 15- and 30 -sec filler intervals consisted of 15 and 30 observation intervals, respectively. Except for the first 1-sec interval in which a signal was never presented, the probability of no signal being presented in any 1 -sec interval was .87 for the 15 -sec retention interval and .91 for the 30 -sec retention interval.

Ss were instructed to repeat the words aloud and were also warned not to rehearse the words during the retention interval. Instructions were essentially identical to those employed by Reitman (1971). In addition, Ss were paid 2 cents for each hit, were penalized 2 cents for each miss, and were penalized 1 cent for each false alarm. Also, 5 cents was given for an average reaction time of less than $450 \mathrm{msec}$ for a block of trials.

\section{Subjects}

In all, there were 20 Ss. (See Table 1 for assignment of Ss to conditions.) Only those Ss who displayed forgetting were tested with the 0-sec retention interval, in order to ascertain whether their "forgetting" may actually have been an inability to type. If a recall score in any condition in which $\mathrm{S}$ participated was less than $75 \%$, he was asked to participate in the 0 -msec condition. Of the 20 Ss tested, half fell below this cutoff mark. S 10 was unable to return.

\section{RESULTS AND DISCUSSION}

In Table 1, the proportion of words correctly recalled is given for each $\mathrm{S}$ for each experimental condition in which he participated. Reaction time and $\mathrm{d}^{\prime}$ are also shown as measures of the detectability of the signal in the filler task.

As shown in Table 1, Ss 1-10 show a substantial amount of forgetting with a 30-sec interpolated discrimination task. As can be seen from Table 1, the low recall scores for the $10 \mathrm{Ss}$ who appeared to forget (Ss 1-10) are not attributable to an inability to type. A Wilcoxon matched-pairs signed-ranks test revealed significant differences between the 30-sec interpolated discrimination task compared to the 0 -sec interval condition and between the latter and the 30 -sec interpolated vigilance task, $T(9)=0, p<.01$, and $T(9)=$ $3.5, \mathrm{p}<.05$, respectively. Although these, and subsequent, statistical tests may violate the independence assumption, the magnitude of the differences appear to be so great that they may overcome this weakness. Thus, approximately half of the Ss showed substantial forgetting when a 30 -sec discrimination task filled the retention interval, and these Ss also showed, on the average, some forgetting, although in some cases perhaps a relatively trivial amount, when a 30 -sec vigilance task filled the retention interval.

Further inspection of Table 1 reveals that the vigilance task appeared to be easier than the discrimination task, since the RT was shorter for the 30 -sec sec vigilance task and the $\mathrm{d}^{\prime}$ was larger. These results were confirmed by a Wilcoxon matched-pairs signed-ranks test comparing the 30 -sec vigilance and 30 -sec discrimination tasks, $\mathrm{T}(19)=27, \mathrm{p}<.01$, for RT, and $\mathrm{T}(19)=29.5, \mathrm{p}<.05$, for $\mathrm{d}^{\prime}$. Furthermore, if we followed Reitman's (1971) argument that slower RTs should be associated with Ss attempting to rehearse, we would expect recall performance following discrimination to be better than that following the vigilance task. However, precisely the opposite was found, $\mathrm{T}(19)=14, \mathrm{p}<.01$, in the proportion of words correctly recalled.

Therefore, we have evidence that the vigilance task was easier than the discrimination task, and the vigilance task yielded better performance on the recall task. This result may be interpreted as support for differential amounts of interference in the recall of verbal material from nonlinguistic acoustic signals. Alternatively, this result may reflect a greater opportunity in vigilance for $S$ to rehearse the verbal material, and may merely indicate that a more difficult task simply takes longer to process and thus allows less time to process the words.

If we dichotomize the data into "forgetters" and "nonforgetters" based on their 30-sec discrimination task performance, as shown in Table 1, there seems to be a suggestion of longer RTs for the "nonforgetters." This would be in line with Reitman's suggestion that superior performance should follow, since the lack of forgetting may indicate covert rehearsal. Comparing the forgetters and nonforgetters on RTs, using a Mann-Whitney U test, fails to yield a significant difference, $U(9,10)=29$, $\mathrm{p}>.05$. In addition, a Spearman's rank correlation between P and RT for the 30-sec discrimination task was only .25. Thus, it is unclear if the longer RTs of the nonforgetters reflect real differences resulting from covert rehearsal of the words and resulting in superior recall performance.

One is uncomfortable performing analyses based on a post hoc partitioning into groups. Nevertheless, these analyses may serve as suggesting evidence or as a guide. The superior recall performance for $S s$ with the apparently easier vigilance task, along with shorter RTs and higher $d^{\prime}$, may be indicative of an S's ability to time-share, and thus covertly rehearse the to-be-remembered material. Finally, the substantial overall amount of forgetting, although less than that found with a standard Peterson \& Peterson (1959) filler task, at the least seriously questions the conclusion that loss of information from short-term memory is not due in any way to the passage of time.

\section{REFERENCES}

Atkinson, R. C., \& Shiffrin, R. M. The control processes of short-term memory. Technical Report No. 173, Institute for Mathematical Studies in the Social Sciences, 1971.

Peterson, L. T., \& Peterson, J. I. Short-term retention of individual verbal items. Journal of Experimental Psychology, $1959,58,193-198$.

Reitman, J. S. Short-term verbal retention with interpolated verbal and non-verbal signal detection. (Doctoral dissertation, The University of Michigan) Ann Arbor, Michigan: University Microfilms, 1969. No.70-14622. Also, Communication No. 262, Mental Health Research Institute, The University of Michigan, 1969.

Reitman, J. S. Mechanisms of forgetting in short-term memory. Cognitive Psychology, 1971, 2, 185-195.

Swets, J. A. (Ed.) Signal detection and recognition by human observers. Contemporary readings. New York: Wiley, 1964.

(Received for publication September 6, 1973.) 